\title{
Simulation of a Condensation Unit for VOC Recovery
}

\author{
Leonardo Vilar Moura
}

\begin{abstract}
The control of volatile organic compounds (VOCs) emissions is of prime importance due to their high toxicity and consequences for health and environment. In this scenario, the use of techniques for recovery or destruction of VOCs are largely investigated in industry and academia. In this study, a condensation unit was proposed to recover formaldehyde from a gas effluent to liquid phase using a modified dehumidification step. A condensation unit composed of theoretical stages in which both water and formaldehyde are continuously condensed was simulated using Scilab software. The results show that, under certain conditions of chilled water (in particular mass flow and temperature), it would be possible to recover a high fraction of formaldehyde (approximately 95\%) in liquid phase, whilst formaldehyde concentration in gas phase decreased from 250 to $35 \mathrm{mg} / \mathrm{m} 3$. As a consequence, a liquid effluent composed of water and formaldehyde is obtained to be further reutilized/recycled or treated by other methods (post-treatment).
\end{abstract}

Index Terms - VOC, recovery, condensation, simulation.

\section{INTRODUCTION}

The volatile organic compounds (VOCs) are well-known compounds with a low vapor pressure at ambient conditions $\left(20^{\circ} \mathrm{C}\right.$ and $\left.1 \mathrm{~atm}\right)$ and major components of air pollution. The VOCs are largely used as solvents and their main sources include industries such as petroleum refineries, pharmaceutical plants, automobile industries, textile manufacturers, and also fuel combustion in urban areas [1]. The main VOCs include chlorohydrocarbons, perfluorocarbons, acetaldehyde, formaldehyde, acetone, benzene, toluene, hexane, and several other carbon-based compounds [2].

The negative effects of VOCs presence in the atmosphere or indoor air are mainly due to their impact on ozone/smog precursors, toxicity and health issues. Health effects may include irritation, headaches, damage to liver, kidney and central nervous system, among others [1,3].

In this scenario, the techniques allowing a decrease in VOCs concentrations as well as process control to avoid emissions are of prime importance. The VOC removal techniques are usually placed in two categories: (a) process and equipment modifications allowing a decrease in VOCs emissions or formation during a certain process or; (b) control techniques in which VOCs are either recovered or decomposed [2].

The process modification is mainly based on rational process design and choice of raw materials, solvents and process parameters in order to minimize the formation or usage of VOCs [2].

Leonardo Vilar Moura, School of Chemical Engineering, University of Campinas, Campinas, Brazil
Conversely, VOCs can be destroyed by employing either thermal or catalytic oxidation or bio-filtration steps. Thermal oxidation, that is, the conversion of VOCs mainly in carbon dioxide $(\mathrm{CO} 2)$ and water $(\mathrm{H} 2 \mathrm{O})$ is known to occur at higher temperatures, thus rendering VOCs destruction an expensive process. In this scenario, catalytic oxidation provides an alternative capable of reducing energy costs by using catalysts to destroy VOCs at lower temperatures [2]. The recovery of VOCs is also an important method of reducing their emissions and, in some cases, recycling could become an attractive economical choice. Among recovery techniques, the most investigated are condensation, absorption, adsorption and membrane separation [2].

Condensation is a technique usually chosen for effluent gases containing concentrations of VOCs around 5,000 ppm or more. The driving force of a typical condensation process is over-saturation, which can be achieved by means of decreasing effluent gas temperature or pressurization [2, 4].

In this work, a condensation process will be investigated to recover formaldehyde (FA) from a gas effluent containing air, formaldehyde and water. Formaldehyde is poisonous VOC produced from the oxidation of methanol, causing several damages to human health and to the environment [5]. Thus, the study of a chemical process to either recover or destroy formaldehyde is of prime importance.

Due to the recommended range of application for a condensation process in terms of effluent mass flow and VOC concentration, a base case will be considered for all simulations. As a result, the description and performance of the condenser unit will be analyzed and discussed in the next sections.

\section{MATERIALS AND METHODS}

For most of the VOC treatment techniques, a preliminary step to reduce stream humidity can be used. When studying a gas effluent charged with formaldehyde and water, an interesting approach could be the total or partial condensation of both formaldehyde and water. In this scenario, a code was written in Scilab software to estimate the amount of condensate recovered (mainly water and formaldehyde) and the final formaldehyde concentration in the gas exit.

- Base case: the parameters of the effluent gas stream before entering the condenser are constant, which include VOC concentration $\left(\mathrm{C}_{\mathrm{FA}}\right)$, temperature $\left(\mathrm{T}_{0}\right)$, volume flow of air $\left(\mathrm{m}_{\mathrm{eff}}\right)$, and pressure $(\mathrm{P})$.

$$
\begin{aligned}
& \mathrm{C}_{\mathrm{FA}}=250 \mathrm{mg} / \mathrm{m}^{3} \\
& \mathrm{~T}_{0}=90^{\circ} \mathrm{C} \\
& \mathrm{m}_{\text {eff }}=2720 \mathrm{~m}^{3} / \mathrm{h} \\
& \mathrm{P}=1 \mathrm{~atm} \\
& \mathrm{G} \text { is the gas phase molar flow }(\mathrm{kg} / \mathrm{h}) \\
& \mathrm{X} \text { and y are molar fractions in liquid and vapor phase, } \\
& \text { respectively. }
\end{aligned}
$$


- Air is a non-condensable gas.

- Heat capacities, heat of condensation and densities are constants along the condenser.

- Liquid-vapor equilibrium is considered in each condensation stage (numbered as 1, 2, etc. in Fig. 1, where $L_{n}$ is the condensate molar flow from stage $n$ ).

- Each stage inside the condenser reaches liquid-vapor equilibrium, and the model used is based on the literature [6].

- The algorithm solved using a code written in Scilab is presented in Fig. 2.

- Cooling fluid is water flowing inside heat-exchanger tubes. The temperatures before and after the condensation unit are calculated based on the condensation temperature [7]

- Overall heat transfer (U) chosen according to the literature [7].

$$
\mathrm{U}=115 \mathrm{~W} /\left(\mathrm{m}^{2} \cdot \mathrm{K}\right)
$$

- The pressure drop is considered negligible.

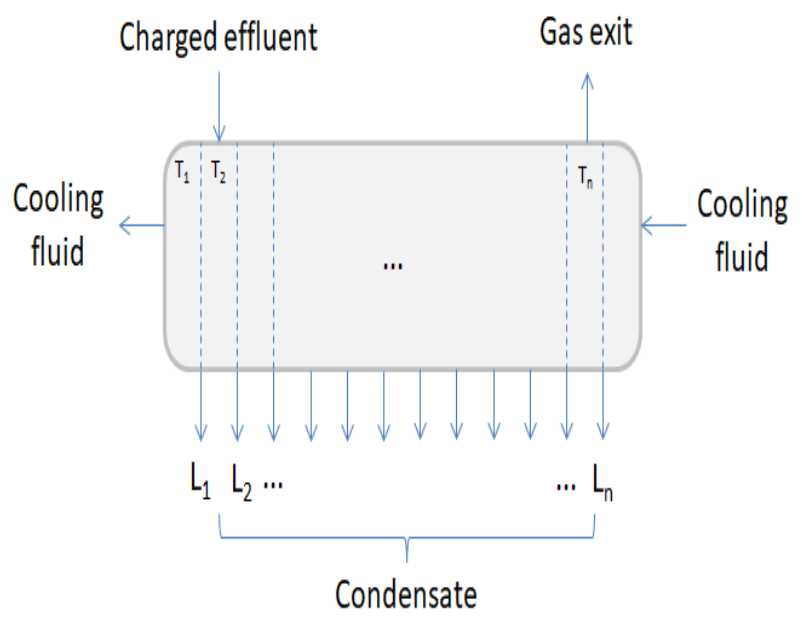

Figure 1: Schema of the condenser unit and its theoretical stages.

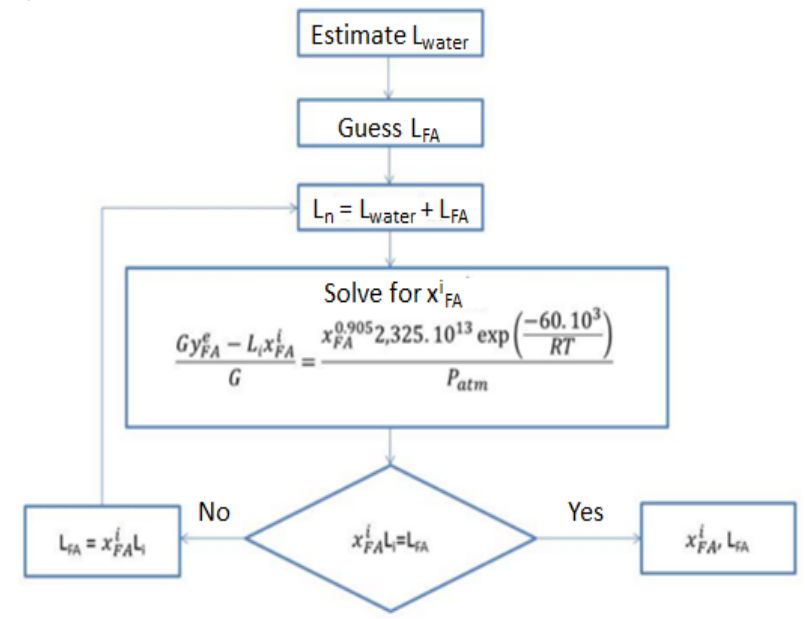

Fig. 2: Method for estimating the amount of formaldehyde condensed per stage.

\section{RESULTS AND DisCUSSION}

Assuming that the temperature of effluent gas varies from $90{ }^{\circ} \mathrm{C}$ to $13{ }^{\circ} \mathrm{C}$, thus the cooling fluid temperature can be estimated [7]. The Table 1 shows the estimated values for these temperatures, along with the total mass flow.

Table 1: Temperatures and mass flow of cooling water.

\begin{tabular}{|c|c|c|}
\hline & Temperature $(\mathrm{K})$ & Mass flow $(\mathrm{kg} / \mathrm{h})$ \\
\hline Fluid inlet & 276.5 & \multirow{2}{*}{7462.3} \\
\cline { 1 - 2 } Fluid exit & 290.4 & \\
\hline
\end{tabular}

Thus, it was possible to estimate general parameters of the condenser, such as surface area, logarithmic mean temperature, and net duty. In the base case, the surface area was $35 \mathrm{~m}^{2}$, which is a feasible value since heat exchanges can accommodate a large number of tubes and have high ratios of area per volume. The total heat required to condensate a significant amount of water and formaldehyde was estimated to be around $120 \mathrm{~kW}$.

In other to present the amount of formaldehyde that was condensed along with water, a case study was conducting with the following variables: mass flow of cooling water, final temperature of the gas effluent and the concentration of formaldehyde in $\mathrm{mg} / \mathrm{m}^{3}$ in the gas exit. The results of this study are presented in Fig. 3.

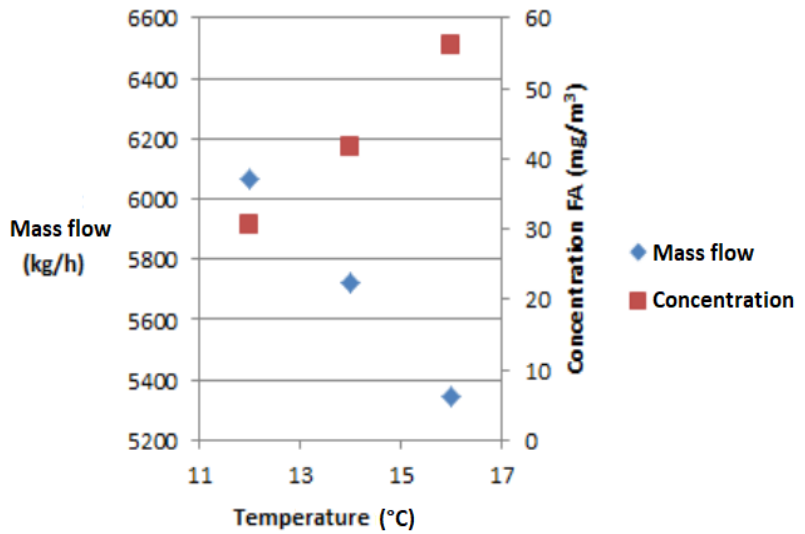

Fig. 3: Study of process variables and the estimated formaldehyde concentration in the gas exit.

The results show that increasing mass flow of cooling water can reduce formaldehyde concentration in gas exit stream, along with a lower condensate temperature. For instance, at around $6000 \mathrm{~kg} / \mathrm{h}$ of cooling water flow, the condensate temperature reaches $12{ }^{\circ} \mathrm{C}$, whilst formaldehyde concentration decreases sharply from $250 \mathrm{mg} / \mathrm{m}^{3}$ at the effluent gas inlet to approximately $35 \mathrm{mg} / \mathrm{m}^{3}$ in the gas exit.

The study of the amount of formaldehyde condensed form gas stream (in \%) and its concentration in gas exit are presented in Fig. 4. By keeping the parameters presented in Table 1 constant, volume flow of effluent gas inlet was varied from 500 to $2720 \mathrm{~m}^{3} / \mathrm{h}$. It is noticeable that for higher volume flow, the amount of FA condensed decreases, which is due to the higher amount of heat capacity required to condense water and formaldehyde. Conversely, formaldehyde concentrations achieve acceptable values in the gas exit, ranging from approximately 12.5 to $22.5 \mathrm{mg} / \mathrm{m}^{3}$ under $500-2720 \mathrm{~m}^{3} / \mathrm{h}$. 


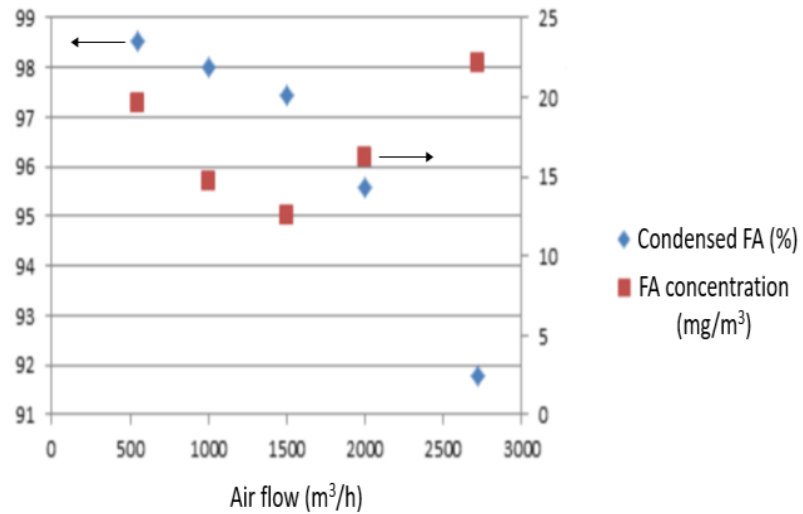

Fig. 4: Study of condensed formaldehyde and its concentration in gas exit in terms of volume flow of gas inlet.

\section{CONCLUSION}

The treatment of gas effluents charged with water and VOC generally requires a preliminary step of dehumidification. The performance of a condensation unit for dehumidification was investigated to remove water and formaldehyde from a gas effluent. A calculation tool has been developed to model the condensation of formaldehyde in condensed water. Considering the base case, it was estimated that a condenser possessing surface area superior to $35 \mathrm{~m}^{2}$ could recover about $95 \%$ of formaldehyde from gas to liquid phase on the bottom of the condenser using about $7500 \mathrm{~kg} / \mathrm{h}$ of chilled water, and thus decrease formaldehyde concentration in gas phase from 250 to about $35 \mathrm{mg} / \mathrm{m}^{3}$. In addition, the condensate containing both water and formaldehyde would require a post-treatment to either recycle (recover) or destroy formaldehyde.

\section{REFERENCES}

[1] Muhammad S. Kamal, Shaikh A. Razzak, Mohammad M. Hossaina (2016). Catalytic oxidation of volatile organic compounds (VOCs) - A review. Atmospheric Environment (ISSN : 1352-2310, 140, 117-134. https://doi.org/10.1016/j.atmosenv.2016.05.031

[2] Faisal I. Khan, Aloke K. Ghoshal (2000). Removal of Volatile Organic Compounds from polluted air. Journal of Loss Prevention in the Process Industries (ISSN : 0950-4230, 13(6), 527-545. https://doi.org/10.1016/S0950-4230(00)00007-3

[3] United States Environmental Protection Agency. Volatile Organic Compounds' Impact on Indoor Air Quality. Retrieved from https://www.epa.gov/indoor-air-quality-iaq/volatile-organic-compoun ds-impact-indoor-air-quality

[4] Vineet K. Gupta, Nishith Verma (2002). Removal of volatile organic compounds by cryogenic condensation followed by adsorption. Chemical Engineering Science (ISSN : 0009-2509, 57 (14), 2679-2696. https://doi.org/10.1016/S0009-2509(02)00158-6

[5] National Center for Biotechnology Information. Formaldehyde compound summary. Retrieved from https://pubchem.ncbi.nlm.nih.gov/compound/Formaldehyde

[6] Manuel Barret, Stephan Houdier, Florent Domine (2011). Thermodynamics of the Formaldehyde-Water and Formaldehyde-Ice Systems for Atmospheric Applications. Atmospheric Environment (ISSN : 1520-5215, 115(3), 307-317. https://doi.org/10.1021/jp108907u

[7] Gunseli S. Shareef, Wiley J. Barbour, Susan K. Lynch, W. Richard Pelt, William M. Vatavuk (1995). In Refrigerated Condensers (Chapter 2). Retrieved from https://www3.epa.gov/ttn/ecas/docs/cs3-1ch2.pdf 